\title{
PHOTOLUMINESCENCE ANALYSIS OF SHALLOW ACCEPTOR IN CdTe FILMS ON GaAs(100) SUBSTRATES
}

\author{
Chikara Onodera $^{1}$ (D), Masaaki Yoshida ${ }^{2}$ (D) \\ ${ }^{1}$ Electronic Engineering Course, \\ Aomori Prefectural Hachinohe Technical Senior High School, \\ 1-2-27 Koyo, Hachinohe, Aomori 031-0801, Japan \\ ycd1ngt@yahoo.co.jp \\ ${ }^{2}$ Department of General Science and Education, \\ Hachinohe National College of Technology, \\ 16-1 Uwanotai, Tamonoki, \\ Hachinohe, Aomori 039-1192, Japan \\ yoshida-g@hachinohe-ct.ac.jp
}

(Received 29 October 2019; in final form 14 April 2021; accepted 11 May 2021; published online 13 July 2021)

\begin{abstract}
In this study, photoluminescence (PL) measurements are performed for analyzing shallow acceptor states in undoped cadmium telluride films on gallium arsenide substrates. PL and time-resolved photoluminescence spectra are analyzed in the vicinity of a $1.55 \mathrm{eV}$ band. The residual impurity concentration in the undoped cadmium telluride film is greater than $1.5 \times 10^{18} \mathrm{~cm}^{-3}$. By analyzing the peak shift of the $1.55 \mathrm{eV}$ band as a function of time after pulsed excitation, the bound-tobound reaction constant for the undoped cadmium telluride film on a gallium arsenide substrate is estimated to be $2.4 \times 10^{7} \mathrm{~s}^{-1}$.
\end{abstract}

Key words: cadmium telluride, photoluminescence, time-resolved photoluminescence, acceptor impurity element

DOI: https://doi.org/10.30970/jps.25.3701

\section{INTRODUCTION}

Thick cadmium telluride (CdTe) epitaxial layers have been investigated owing to its potential applications in $\mathrm{X}$ - and $\gamma$-ray detectors [1]. Meanwhile, CdTe films on gallium arsenide (GaAs) substrates have been investigated for their application as substrates for mercury cadmium telluride ( $\mathrm{HgCdTe})$ infrared detectors [2]. Impurity analysis is crucial to CdTe films because both doped and undoped impurities significantly affect the performances of devices incorporating CdTe films.

Photoluminescence (PL) measurement is an excellent nondestructive tool for characterizing semiconductors and is widely used to analyze the impurity state and defect structure of semiconductors. CdTe crystals exhibit sharp emission lines due to donor and acceptor bound exitons, edge emission bands [3] [free-to-acceptor (FA) emission, donor-acceptor-pair (DAP) emission], and deep-level bands (1.42 eV band [4] and $1.47 \mathrm{eV}$ band [5]). These emissions can be used to characterize intrinsic uncontrolled impurities and defects deviations from the stoichiometry in the CdTe crystal as well as to determine the energy levels of donors and acceptors.

In our previous study, by analyzing PL spectra in metal organic chemical-vapor deposition (MOCVD)grown CdTe films on (100) GaAs substrates, we established that the origin of the deep-acceptor state of the 1.42 $\mathrm{eV}$ band was presumably a complex comprising a Cdvacancy and a chlorine $(\mathrm{Cl})$ donor atom [6]. Moreover, we reported that the $1.47 \mathrm{eV}$ band overlapped with the $1.42 \mathrm{eV}$ band, and that its intensity decreased with heat treatment [7].

In our previous studies, in the vicinity of $1.55 \mathrm{eV}$, a DAP emission was observed in undoped MOCVD grown CdTe films on (100) GaAs substrates [6-8]. In molecular beam epitaxy (MBE)-grown CdTe layers on GaAs substrates, sharp DAP and FA emissions were observed, and their acceptor origin was a complex comprising a Cd-vacancy and a $\mathrm{Cl}$ donor atom, assigned by analyzing linear polarized PL spectra [9]. Moreover, to estimate the ionization energy of a Cd-vacancy and two $\mathrm{Cl}$ donors on tellurium ( $\mathrm{Te}$ ) sites in a Cl-doped bulk $\mathrm{CdTe}$, temperature-dependent PL measurements were performed [10].

However, a time-resolved photoluminescence (TRPL) of the DAP emission has not been reported in previous studies regarding CdTe films on GaAs substrates. Therefore, we herein provide an interpretation of the DAP emission based on experimental studies regarding the decay kinetics in CdTe films on GaAs substrates.

\section{SAMPLE PREPARATION AND EXPERIMENTAL METHODS}

The details of the MOCVD apparatus are described in Fig. 1. A vertical flow cold wall MOCVD system was utilized for growing CdTe films. The MOCVD system comprised two different flow paths connected to the growth reactor designed for precursor transport to suppress pre-reactions to achieve a uniform film growth. The first one was a $\mathrm{Cd}$ precursor path. The second path was employed to deliver a Te precursor and hydrogen $\left(\mathrm{H}_{2}\right)$ gas. The gas flow tubes were made of stainless steel.

Dimethylcadmium (DMCd) diluted with helium $(\mathrm{He})$ at a concentration of $0.13 \%$ from Nippon Sanso 
Corporation was used as the $\mathrm{Cd}$ precursor. The Te precursor used was dimethyltellurid (DMTe) from Tri Chemical Laboratory Incorporated; it was stored at $0^{\circ} \mathrm{C}$ in a constant-temperature bath and fed by bubbling with purified $\mathrm{H}_{2}$ gas in containers. The DMTe was delivered to the growth reactor using $\mathrm{H}_{2}$ gas as the carrier gas. The DMCd and DMTe flows were controlled using massflow-controllers (MFC).

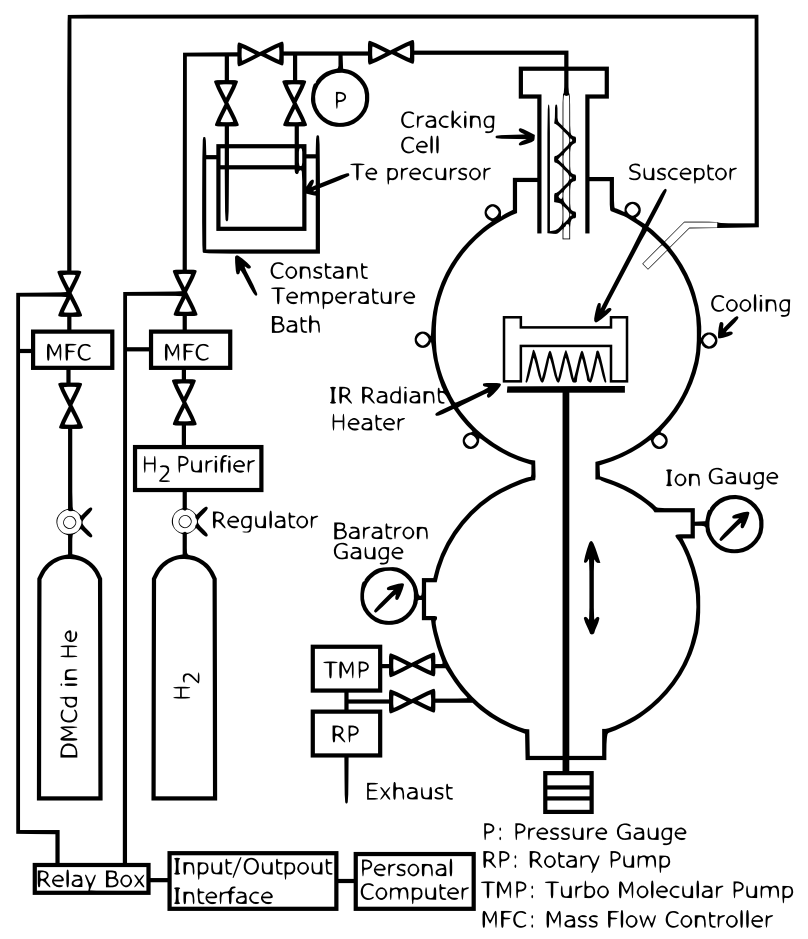

Fig. 1. Low-pressure MOCVD apparatus

The DMTe and $\mathrm{H}_{2}$ gas were supplied from a vertical inlet. The DMCd was injected from the oblique upside to the susceptor. We used a graphite susceptor that was heated by an infrared radiant lamp underneath the susceptor. We used the precracking method for dissolving the DMTe prior to the deposition of CdTe films because the CdTe film growth did not proceed at the substrate temperature of approximately $350^{\circ} \mathrm{C}$ under low-pressure conditions owing to the high decomposition temperature of DMTe. A schematic illustration of the growth reactor with a cracked DMTe precursor is shown in Fig. 1 [11].

Cr-doped semi-insulating (100)GaAs $(1 \mathrm{~cm} \times 1 \mathrm{~cm})$ misoriented by $3^{\circ}$ toward the nearest (110) was used as the substrate. It has been proven that high-quality CdTe films can be grown on GaAs substrates despite the significant lattice mismatch $(14.6 \%)$ between them [12]. The GaAs (100) face was superior to the GaAs (111) because the twinned region can be excluded from the CdTe films. The misalignment of the GaAs surface toward the (110) suppressed hillock formation [12].

The substrates were alternately degreased in a trichloroethylene $\left(\mathrm{C}_{2} \mathrm{HCl}_{3}\right)$ solution and acetone $\left(\mathrm{C}_{3} \mathrm{H}_{6} \mathrm{O}\right)$ for $5 \mathrm{~min}$ each, then they were rinsed in ethanol. The substrates were cleaned with deionized water via ultrasonic cleaning. Subsequently, the substrates were etched in a 5:1:1 solution of sulfuric acid $\left(\mathrm{H}_{2} \mathrm{SO}_{4}\right)$, hydrogen peroxide $\left(\mathrm{H}_{2} \mathrm{O}_{2}\right)$, and water $\left(\mathrm{H}_{2} \mathrm{O}\right)$ at $40^{\circ} \mathrm{C}$ for $1 \mathrm{~min}$. They were rinsed in deionized water and boiled in a hydrochloric acid $(\mathrm{HCl})$ solution.

After etching, the substrates were placed immediately on the susceptor in the reactor. The reactor was pumped down to $10^{-6}$ Torr using a turbo-molecular pump. Prior to growth, the substrates were thermally cleaned at $550^{\circ} \mathrm{C}$ for $5 \mathrm{~min}$ in the reactor in a $\mathrm{H}_{2}$ gas flow to reduce the oxidized surface. At the end of this annealing, the $\mathrm{H}_{2}$ gas continued flowing while the susceptor cooled to the growth temperature. When the susceptor had cooled to the growth temperature, DMTe was introduced into the reactor. CdTe growth was started by introducing DMCd to the reactor. The CdTe growth was terminated by stopping the supply of the DMCd to the reactor. After this, the DMTe supply to the reactor was immediately termineted. At the end of the $\mathrm{CdTe}$ growth, $\mathrm{H}_{2}$ gas was supplied continuously until the susceptor cooled to the room temperature.

The growth temperature was $350^{\circ} \mathrm{C}$, and the cracking temperature was approximately $500^{\circ} \mathrm{C}$. The growth pressure was 5 Torr, and the growth duration was 1 $\mathrm{h}$ after the DMCd introduction. The flow rate of the $\mathrm{H}_{2}$ carrier gas was $70 \mathrm{cc} / \mathrm{min}$. The flow rate of $\mathrm{H}_{2}$ gas for the substrate thermal cleaning and cooling was 70 $\mathrm{cc} / \mathrm{min}$, whereas the flow rates of DMCd and DMTe were $5.80 \times 10^{-6}$ and $1.16 \times 10^{-5} \mathrm{~mol} / \mathrm{min}$, respectively. The feed molar ratio of DMTe to DMCd was set to 2 .

To confirm crystallization, $\theta-2 \theta$ X-ray diffraction (XRD) measurement was performed on the samples using Cu $K \alpha_{1}(1.5405 \AA)$ and $\mathrm{Cu} K \alpha_{2}(1.5443 \AA)$ radiation from $20^{\circ}$ to $70^{\circ}$ using the RAD-B system of Rigakudenki Co. Ltd. The crystalline uniformity of the CdTe films was analyzed based on the full width at half-maximum (FWHM) of the (400) diffraction from the X-ray rocking curves.

The surface morphology of the CdTe films was analyzed via visual inspection and using scanning electron microscopy (SEM, JEOL JSM-L5S). The thickness of the CdTe films was obtained from SEM observations of the cleaved surface with the measurement error of $0.02 \mu \mathrm{m}$.

The intrinsic uncontrolled impurities and defects of the CdTe films were analyzed from the PL spectra. We used undoped as-grown CdTe films on GaAs(100) substrates for PL spectrum and TRPL analysis. The sample was immersed in liquid He at $4.2 \mathrm{~K}$ for all measurements.

$\mathrm{PL}$ measurements were performed using a $\mathrm{He}-\mathrm{Cd}$ laser $(441.6 \mathrm{~nm}, 50 \mathrm{~mW})$ as an excitation source in addition to a $1 \mathrm{~m}$ Jobin-Yvon single-grating monochromator using a conventional rock-in system with the energy resolution of $0.1 \mathrm{meV}$.

The bound-to-bound reaction constants of the CdTe films were estimated using TRPL measurements. The TRPL measurements were performed at $4.2 \mathrm{~K}$ using an $\mathrm{N}_{2}$ laser (pulse width and repetition rate of $1 \mathrm{~ns}$ and $10 \mathrm{~Hz}$, respectively) as an excitation source. Moreover, a $1 \mathrm{~m}$ Jobin-Yvon single-grating monochromator containing a conventional boxcar integrator with the energy 
resolution of $0.1 \mathrm{meV}$ was employed. The laser $\mathrm{N}_{2}$ power was controlled using neutral-density filters.

\section{RESULTS AND DISCUSSION}

The XRD patterns exhibited peaks at $2 \theta=27.49^{\circ}$ and $56.74^{\circ}$ which corresponded to reflections on the (200) and (400) planes of cubic CdTe, respectively, without additional shallow diffraction peaks. The structure of the $\mathrm{CdTe}$ film was found to be cubic with a preferential orientation of the (100) plane parallel to the GaAs substrates without other orientations or phases.

The FWHM of the (400) diffraction from the X-ray rocking curve of the CdTe film was estimated to be 540 arcsec, and peak separation was not observed for $\mathrm{Cu} K \alpha_{1}$ and $\mathrm{Cu} K \alpha_{2}$. By contrast, the GaAs substrate used in this study had the FWHM of 331 arcsec, and peak separation was observed for $\mathrm{Cu} K \alpha_{1}$ and $\mathrm{Cu} K \alpha_{2}$. This indicates the poor crystalline uniformity of the CdTe film compared with the GaAs substrates.

The CdTe layer was visually uniform and covered the (100) GaAs substrate surface. Moreover, the CdTe fi$\mathrm{lm}$ exhibited a shiny, mirror-like surface. The CdTe film exhibited a flat surface without any indication of hillocks, as confirmed via SEM.

The grown CdTe film was $1.2 \mu \mathrm{m}$ thick, as estimated via SEM.

Prior to assessing the TRPL properties in an undoped MOCVD-as-grown CdTe film, the typical PL properties must first be determined. Figure 2 shows the PL spectrum for the undoped CdTe layer grown on a GaAs(100) substrate using DMCd and DMTe at $350^{\circ} \mathrm{C}$. The spectrum was dominated by a sharp neutralacceptor bound-exciton emission at $1.5904 \mathrm{eV}$, denoted as $\mathrm{A}_{1}^{1}$, with the line width of $0.9 \mathrm{meV}$. A neutral-donor bound-exciton at $1.5931 \mathrm{eV}$, denoted as $\mathrm{D}_{1}^{1}$, with the line width of $1.4 \mathrm{meV}$ was observed. Furthermore, we observed a heavy-hole free-exciton emission at the highenergy shoulder of the neutral-donor bound-exciton emissions. Moreover, the light-hole free-exciton emission at the high-energy shoulder of the heavy-hole free-exciton emission was weak. A neutral-acceptor bound-exciton emission near $1.5904 \mathrm{eV}$ was observed in Cl-doped CdTe bulk crystals $[10,13]$. Meanwhile, a neutral-donor boundexciton emission near $1.5931 \mathrm{eV}$ was observed in $\mathrm{Cl}-$ doped CdTe bulk crystals [10, 13]. These features indicate that the $\mathrm{CdTe}$ film contained $\mathrm{Cl}$ complex acceptors and $\mathrm{Cl}$ donors.

In comparison, in the lower photon energy range of 1.51-1.58 eV, a DAP emission was observed. In the much lower photon energy range of the DAP emission, a deeplevel the $1.4 \mathrm{eV}$ emission was observed.

To clearly distinguish the DAP and $1.4 \mathrm{eV}$ emissions, we performed the Lorentzian deconvolution. We simulated the total shape of the DAP and the $1.4 \mathrm{eV}$ emissions using the Poisson distribution combined with Lorentzian lines for each individual line. The intensity of the $n$th phonon replicas can be described by the Poisson distribution, as follows [4]

$$
I(n)=I_{0} e^{-S} \frac{S^{n}}{n !},
$$

where $S$ is the Huang-Rhys coupling parameter, and $I_{0}$ is a constant. The deconvolved band shapes of the DAP and the $1.4 \mathrm{eV}$ emissions are plotted in the inset of Fig. 2, where the broken lines indicate the Lorentzian deconvolutions.

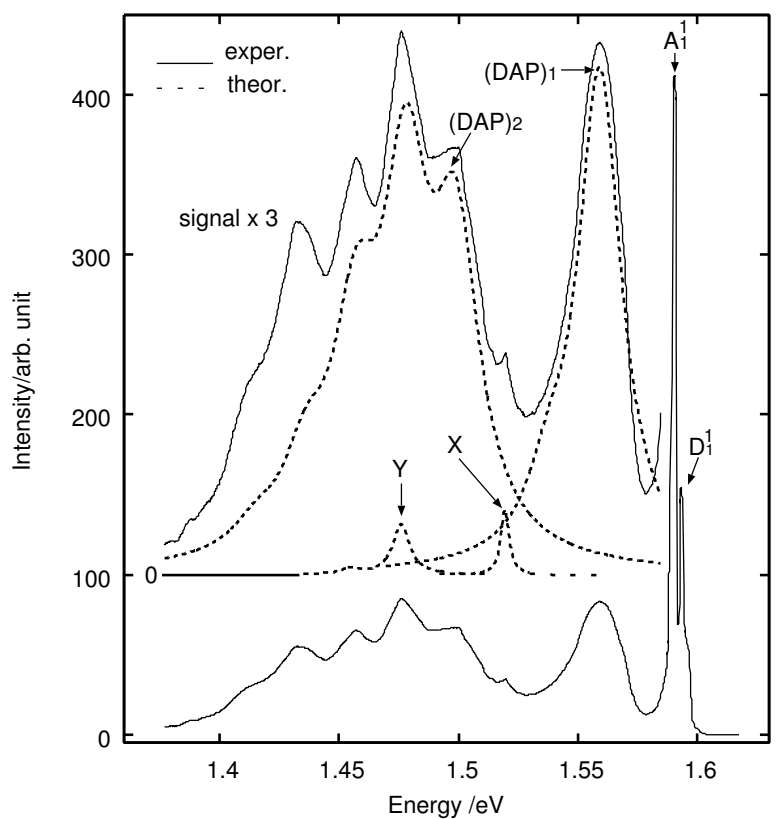

Fig. 2. Typical photoluminescence spectra obtained at $4.2 \mathrm{~K}$ on the CdTe layer of (100) GaAs $1.2 \mu \mathrm{m}$ thick. The inset shows a deconvolved spectrum based on the Poisson distribution combined with Lorentzian lines. The broken lines indicate the Lorentzian deconvolutions in the 1.519, 1.47, and $1.42 \mathrm{eV}$ bands

A broad DAP emission band, denoted as (DAP) 1 was observed near $1.559 \mathrm{eV}$ together with its longitudinal optical (LO) phonon replicas. The LO phonon energy of CdTe was $21 \mathrm{meV}$. The best fit was obtained for the linewidth of $11 \mathrm{meV}$ and the Huang-Rhys coupling parameter of 0.12 . The peak energy of the 0-LO line was estimated to be $1.559 \mathrm{eV}$. Based on the origin of the acceptor state of the $1.42 \mathrm{eV}$ band, the origin of the acceptor state of the DAP emission was presumably a complex comprising a vacancy on the $\mathrm{Cd}$ sublattice and a $\mathrm{Cl}$ donor [9].

The result indicates that the $1.4 \mathrm{eV}$ emission comprised a $1.47 \mathrm{eV}$ band, denoted as $\mathrm{Y}$, and a $1.42 \mathrm{eV}$ band, denoted as (DAP) $)_{2}$. The intensity ratio of the $1.47 \mathrm{eV}$ band to the $1.42 \mathrm{eV}$ band was estimated to be 0.045 . The $1.42 \mathrm{eV}$ band comprised a zero-phonon (0-LO) line followed by four phonon replicas (1-LO to 4-LO), each separated by a phonon energy of approximately 21 $\mathrm{meV}$. The best fit was obtained for the linewidth of 11.5 $\mathrm{meV}$ and the Huang-Rhys coupling parameter of 1.18 . The peak energy of the 0-LO line was estimated to be $1.499 \mathrm{eV}$. Based on our previous study, the origin of the 
acceptor state of the $1.42 \mathrm{eV}$ band was presumably a complex comprising a vacancy on the $\mathrm{Cd}$ sublattice and a $\mathrm{Cl}$ donor [6].

The $1.47 \mathrm{eV}$ band comprised a zero-phonon (0-LO) line, followed by two phonon replicas (1-LO and 2-LO), each separated by a phonon energy of approximately 21 $\mathrm{meV}$. The best fit was obtained for the linewidth of 4.3 $\mathrm{meV}$ and the Huang-Rhys coupling parameter of 0.12 . The peak energy of the 0-LO line was estimated to be $1.477 \mathrm{eV}$.

In Fig. 2, the characteristics of the emission peak at $1.519 \mathrm{eV}$, denoted as X, are unknown currently.

The impurity concentrations $(N)$ for the DAP emission and the $1.42 \mathrm{eV}$ band can be determined from the DAP emission and the $1.42 \mathrm{eV}$ peak photon energies. We used the following equation in our calculations [15]:

$$
E_{\mathrm{DA}}=E_{\mathrm{g}}-\left(E_{\mathrm{A}}+E_{\mathrm{D}}\right)+\frac{e^{2}}{4 \pi \varepsilon r}
$$

where $E_{\mathrm{A}}$ is the activation energy of the acceptor, $E_{\mathrm{D}}$ is the activation energy of the donor, $E_{\mathrm{g}}$ is the energy gap of CdTe at $4.2 \mathrm{~K}$, and $e^{2} / 4 \pi \varepsilon r$ is the Coulomb energy from the donor to the acceptor, $e$ is the electron charge, and $\varepsilon$ is the dielectric constant (10.2) [16]. $N$ can be calculated from the equation $(4 \pi / 3) r^{3}=1 / N$, [7] where $r$ is the mean spacing between the impurities. For the $1.42 \mathrm{eV}$ band, the value of $N$ was estimated to be $1.49 \times 10^{18} \mathrm{~cm}^{-3}$, where $E_{\mathrm{A}}=120 \mathrm{meV}$ [10] and $E_{\mathrm{D}}=14 \mathrm{meV}$ [16] were used. For the DAP emission, the value of $N$ was estimated to be $1.47 \times 10^{17} \mathrm{~cm}^{-3}$, where $E_{\mathrm{A}}=45 \mathrm{meV}$ [10] and $E_{\mathrm{D}}=14 \mathrm{meV}$ [17] were used. Here, we used the band gap energy of CdTe, i.e., 1.606 eV [18]. By analyzing the PL peak energy, we established that the intrinsic-uncontrolled impurity concentration in the undoped CdTe film exceeded $1.5 \times 10^{18} \mathrm{~cm}^{-3}$. These impurities were presumably due to the residual impurities contained in alkyl sources or from the growth system.

\begin{tabular}{lcccc}
\hline$t(\mu \mathrm{s})$ & $\Delta E(\mathrm{meV})$ & $R(\mathrm{~nm})$ & $W_{0}\left(\mathrm{~s}^{-1}\right)$ & $N\left(\mathrm{~cm}^{-3}\right)$ \\
\hline 5 & 2.2 & 14 & $1.9 \times 10^{7}$ & $7.9 \times 10^{16}$ \\
10 & 3.1 & 16 & $2.0 \times 10^{7}$ & $5.9 \times 10^{16}$ \\
15 & 3.8 & 17 & $2.5 \times 10^{7}$ & $4.7 \times 10^{16}$ \\
20 & 4.0 & 18 & $2.4 \times 10^{7}$ & $4.3 \times 10^{16}$ \\
\hline
\end{tabular}

Table 1. Values of emission peak shift $\Delta E$ for 0 -LO line of $1.55 \mathrm{eV}$ band, donor-acceptor pair (DAP) separations $R$, bound-to-bound reaction constants $W_{0}$, and impurity concentrations $N$ for different times after pulsed excitation

To estimate the bound-to-bound reaction constant for the undoped CdTe film on a GaAs substrate, we measured the TRPL for the DAP emission. Figure 3 shows the change in the emission spectra for the DAP emission band at $4.2 \mathrm{~K}$ with time after pulsed excitation in a CdTe film on a $\operatorname{GaAs}(100)$ substrate. The DAP emission band comprised a zero-phonon (0-LO) line, followed by one-phonon replicas (1-LO). They were separated by a phonon energy of approximately $21 \mathrm{meV}$. The peak energy of the 0-LO line was $1.559 \mathrm{eV}$. A phonon replica
(1-LO) peak at the low-energy tail of the DAP emission peak was observed. We simulated the total shape of the DAP emission band using the Poisson distribution combined with Lorentzian lines for each individual line. Furthermore, the deconvolved line shapes of 1-LO were plotted as broken lines. as shown in Fig. 3. The best fit was obtained for the linewidth of $11.0 \mathrm{meV}$ and the Huang-Rhys coupling parameter of 0.25 at $0 \mu$ s after pulsed excitation. The value of $S$ was greater than that of the continuous excitation shown in Fig. 2. The difference in the Huang-Rhys coupling parameter between the pulsed and continuous excitations was presumably the difference in the excitation density between them.

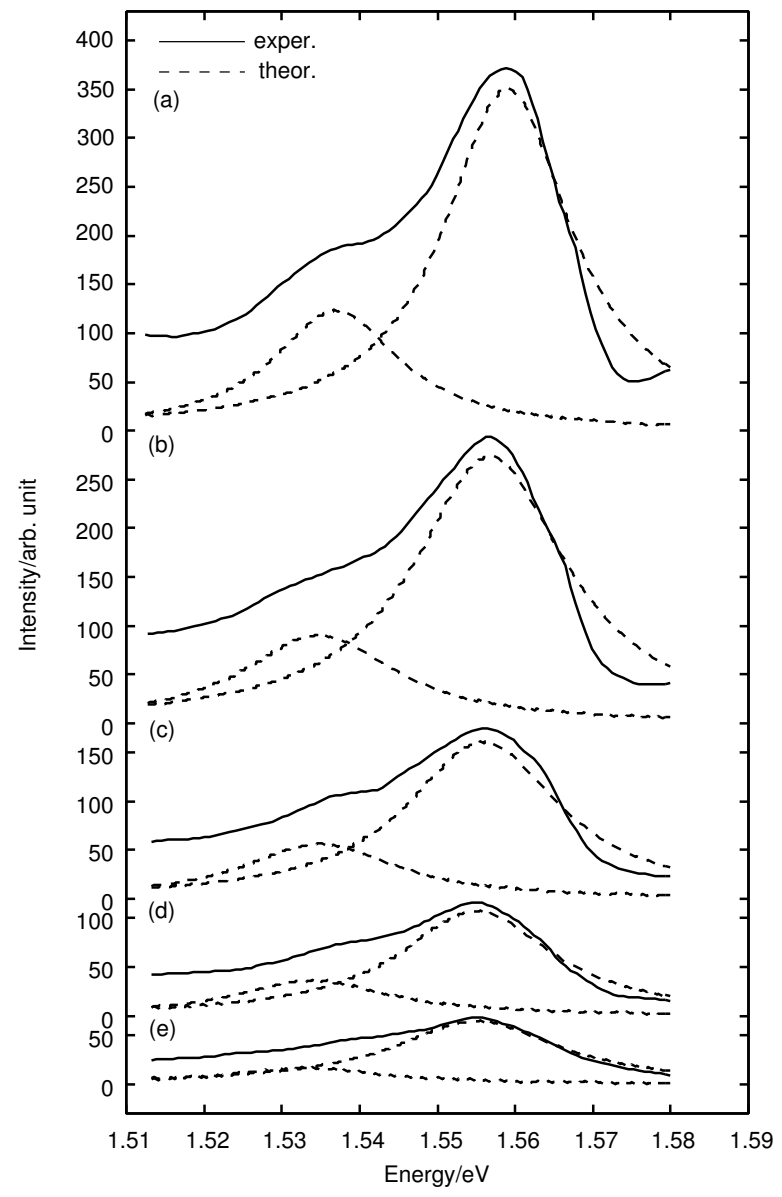

Fig. 3. Spectral changes in the $1.55 \mathrm{eV}$ donor-acceptor pair (DAP) emission band of the CdTe film after the pulsed excitation at (a) $0 \mathrm{\mu s}$, (b) $5 \mathrm{\mu s}$, (c) $10 \mu \mathrm{s}$, (d) $15 \mu \mathrm{s}$, and (e) 20 ps. The broken lines indicate the Lorentzian deconvolutions in the $1.55 \mathrm{eV}$ DAP emission band

The DAP emission band peaks including their LOphonon replicas shifted to a lower energy as time progressed after pulsed excitation was applied. Table 1 shows a summary of the values of the emission peak shi$\mathrm{ft} \Delta E$ for the 0-LO line of the DAP emission band. The 0-LO line of the DAP emission shifted by $4.0 \mathrm{meV}$ to a lower energy of 20 us after pulsed excitation was applied. Using the time-dependent energy peak shift observed in the TRPL of the DAP emission band, the bound-tobound reaction constant $W_{0}$ was calculated using the 
following equation, [5]

$$
\ln \left(W_{0}\right)=\frac{4 E_{\mathrm{D}}}{E_{\mathrm{cmax}}}+\ln \left(1-\frac{E_{\mathrm{cmax}}}{E_{\mathrm{D}}}\right)-\ln t
$$

where $E_{\text {cmax }}$ is the Coulomb energy at the position of the emission peak at time $t$. Table 1 shows a summary of the values of the DAP separation $R$ and $W_{0}$ as a function of time after pulsed excitation.

At $t=20 \mu \mathrm{s}$, for a donor binding energy $E_{\mathrm{D}}$ of $14 \mathrm{meV},[16] W_{0}$ was calculated to be $2.4 \times 10^{7} \mathrm{~s}^{-1}$; this value was lower than that of undoped p-type bulk CdTe for the $1.42 \mathrm{eV}$ DAP band $\left(W_{0}=5 \pm 1 \times 10^{7} \mathrm{~s}^{-1}\right)$ [18].

The impurity concentrations in the undoped CdTe films on GaAs substrates estimated from the peak energies of the 0-LO line of the DAP emission as a function of time after pulsed excitation are listed in Table 1 . The value of $N=4.3 \times 10^{16} \mathrm{~cm}^{-3}$ at $20 \mu \mathrm{s}$ is greater than that in the case of undoped p-type bulk CdTe for the $1.42 \mathrm{eV}$
DAP band $\left(N=2.5 \times 10^{16} \mathrm{~cm}^{-3}\right)[19]$.

\section{CONCLUSIONS}

To investigate the nature of the DAP emission in the vicinity of $1.55 \mathrm{eV}$ in undoped $\mathrm{CdTe}$ films on GaAs (100) substrates, we measured the PL spectra and TRPL of CdTe films on GaAs (100) substrates. The residual impurity concentration in an undoped CdTe film on a GaAs substrate exceeded $1.5 \times 10^{18} \mathrm{~cm}^{-3}$. The deconvolved linewidth for each phonon replica in the DAP emission band was $11.0 \mathrm{meV}$. The Huang-Rhys coupling parameter was estimated to be 0.25 , based on the total line-shape analysis of the DAP emission band using Lorentzian deconvolution. Based on the TRPL analysis, $W_{0}$ was $2.4 \times 10^{7} \mathrm{~s}^{-1}$. The value of $W_{0}$ was greater than that of the $1.42 \mathrm{eV}$ band in an undoped p-type bulk CdTe [19].
[1] K. Yasuda et al., Jpn. J. Appl. Phys. 41, L1109 (2002); https://doi.org/10.1143/JJAP.41.L1109.

[2] I. B. Bhat, N. R. Taskar, S. K. Ghandhi, J. Vac. Sci. Technol. A 4, 2230 (1986); https://doi.org/10.1116/ 1.574060 .

[3] S. H. Song, J. Wang, Y. Ishikawa, S. Seto, M. Isshiki, J. Cryst. Growth 237-239, 1726 (2002); https://doi . org/10.1016/S0022-0248(01) 02319-3.

[4] W. Stadler et al., Phys. Rev. B 51, 10619 (1995); https : //doi.org/10.1103/PhysRevB.51.10619.

[5] P. J. Dean, G. M. Williams, G. Blackmore, J. Phys. D 17, 2291 (1984); https://doi.org/10.1088/0022-3727/17 /11/016.

[6] C. Onodera, M. Yoshida, T. Taguchi, Jpn. J. Appl. Phys. 49, 081201 (2010); https://doi.org/10.1143/JJAP.4 9.081201

[7] C. Onodera, M. Yoshida, T. Taguchi, Jpn. J. Appl. Phys. 49, 071201 (2010); https://doi.org/10.1143/JJAP.4 9.071201

[8] C. Onodera, M. Ekawa, T. Taguchi, J. Cryst. Growth 99, 459 (1990); https : //doi .org/10.1016/0022-0248(90) 9 0564- 2 .

[9] T. A. Kuhn, W. Ossau, R. N. Bicknell-Tassius, G. Landwehr, Appl. Phys. Lett. 55, 2637 (1989); https://doi. org/10.1063/1.101960.

[10] H. Y. Shin, C. Y. Sun, J. Cryst. Growth 186, 354 (1998); https://doi.org/10.1016/S0022-0248(97)00539-3.
[11] K. Ohba, C. Onodera, T. Taguchi, in Defect Control in Semiconductors (Elsevier Science, 2012), p. 1349; https : //doi.org/10.1016/B978-0-444-88429-9.50063-X.

[12] G. Kartopu, S. J. C. Irvine, in Metalorganic Vapour Phase Epitaxy (MOVPE): Growth, Materials Properties, and Applications, edited by S. J. C. Irvine and P.. Capper (John Wiley \& Sons Ltd, Hoboken, NJ, 2020), p. 325.

[13] T. Taguchi, C. Onodera, Mater. Sci. Forum 65-66, 235 (1990); https://doi.org/10.4028/www.scientific .net/MSF.65-66.235.

[14] T. Taguchi, T. Yokogawa, H. Yamashita, Solid State Commun. 49, 551 (1984); https://doi.org/10.1016/ 0038-1098 (84) 90189-3.

[15] F. Molva, J. P. Chamonal, J. L. Pautrat, Phys. Status Solidi B 109, 635 (1982); https://doi.org/10.1002/ps sb. 2221090222 .

[16] O. Madelung, in Semiconductors - Basic Data, 2nd rev. ed. (Springer, Berlin, 1996), p. 186.

[17] J. M. Francou, K. Saminadayar, J. L. Pautrat, Phys. Rev. B 41, 12035 (1990); https://doi.org/10.1103/Ph ysRevB.41.12035.

[18] R. E. Halsted, M. R. Lorenz, B. Segall, J. Phys. Chem. Solids 22, 109 (1961); https://doi.org/10.1016/0022 -3697 (61) 90249-9.

[19] T. Taguchi, J. Shirafuji, Y. Inuishi, Jpn. J. Appl. Phys. 12, 1558 (1973); https://doi.org/10.1143/JJAP.12. 1558. 


\title{
ФОТОЛЮМІНЕСЦЕНТНИЙ АНАЛІЗ МІЛКОГО АКЦЕПТОРА В ПЛІВКАХ СdТе НА ПІДКЛАДКАХ GaAs (100)
}

\author{
Чікара Онодера ${ }^{1}$, Масаакі Йошіда $^{2}$ \\ ${ }^{1}$ Старша технічна школа, Гачіноге, префектура Аоморі, Японія \\ ${ }^{2}$ Начіоналъний технологічний коледж, Гачіноге, префектура Аоморі, Японіл
}

У цьому дослідженні виміряно фотолюмінесценцію (ФЛ) для аналізу мілких акцепторних станів у нелегованих плівках телуриду кадмію на підкладках з арсеніду галію. ФЛ та часо-розділені спектри фотолюмінесценції розглянуто в околі смуги 1.55 еВ. Залишкова концентрація домішок у легованій плівці телуриду кадмію перевищує $1.5 \times 10^{18} \mathrm{~cm}^{-3}$. Аналізуючи зсув піка смуги $1.55 \mathrm{eB}$ як функцію часу після імпульсного збудження, ми оцінили константу реакції між зв'язаними станами для нелегованої плівки телуриду кадмію на підкладці з арсеніду галію як $2.4 \times 10^{7} \mathrm{c}^{-1}$.

Ключові слова: телурид кадмію, фотолюмінесценція, часо-розділена фотолюмінесценція, акцепторний домішковий елемент. 